\title{
Comentário X
}

\section{Raquel Glezer}

Departamento de História/Faculdade de Filosofia, Letras e Ciências Humanas/Universidade de São Paulo

Museus históricos como laboratórios de História? .

O convite do Museu Paulista da Universidade de São Paulo para discutir o longo, complexo e erudito texto do Prof. Dr. Ulpiano T. Bezerra de Meneses, Do teatro da memória ao laboratório da História: a exposição museológica e o conhecimento histórico, foi honrosa e muito considerável surpresa! Não sou museóloga por formação ou opção profissional. Não tenho experiência profissional ou leifuras que possam ser contrapostas às suas e também não há tempo suficiente para realizar o que nunca esteve em meu horizonte de preocupações - leituras específicas sobre o assunto, para absorver as formulações teóricas que cercam as atividades museológicas.

O texto, estruturado do geral para o particular, vai de "O teatro da memória" às "Premissas", da "Exposição histórica" à "História e museu histórico: o laboratório da História". Explora em itens e subitens os múltiplos aspectos das teorias museológicas e apoiado em abundante bibliografia contemporânea, propõe como diretrizes para museus históricos a sua transformação em recurso para fazer História com objetos e o ensino de como se faz História com os objetos.

Não pretendo endossar ou questionar suas posições teoricamente. As considerações que com brevidade aqui arrolo, limitadas pelo conhecimento e pelo espaço disponivel, estão apenas em dois níveis: o primeiro é o do visitante de museus; o segundo discute algumas posições de historiadores sobre campos que estes consideram correlatos ao seu. 
Intelectualmente, museus são, a meu ver, espaços privilegiados de trabalho multidisciplinar, complexos e especializados, que exigem para a sua direção, formação erudita na respectiva área de especialidade. Importa tanto o conhecimento do conteúdo dos acervos, dos objetos e seu valor relativo, das formas de aquisição, da inserção social que permitiu sua produção e conforme o caso, também o seu uso, quanto os critérios subjacentes à sua seleção como objeto museológico. Além, é claro, do valor social do ambiente do museu e do que ele nos diz a respeito da sociedade que o criou e mantém.

Um museu, qualquer que seja seu conteúdo e sua organização espacial, em estruturação simples ou complexa, temático ou específico, dotado de equipamento sofisticado de comunicação com o público ou não, é um espaço único de memória e de conhecimento.

Desde os mais simples e despojados museus que existem no país, com acervos formados aleatoriamente - sobreviventes de injunções políticas e abstinência juridica que permitem a algumas pessoas considerarem privados os bens públicos - abandonados à própria sorte, sem verbas e sem quadros profissionais especializados, contando apenas com a colaboração e boa vontade dos que neles trabalham, até os mais complexos e sofisticados museus que existem em alguns países, a sensação que me domina ao entrar em um deles é sempre a de que ali, naquele espaço institucionalizado, surgirão sensações emocionantes, prazerosas - uma experiência nova de conhecimento, insubstituivel.

As pessoas vão aos museus para entreter-se culturalmente e para apreender e compreender. Eventualmente, algo desconhecido passa a fazer parte do seu conhecimento; objetos diversos dos do cotidiano, ou mesmo objetos do cotidiano, são vistos e apreciados de forma diferente porque estão em outra disposição, outro contexto, outra configuração. Sistemático ou não, há algum esforço de leitura, de aprendizagem, de identificação, de reconhecimento da imensa capacidade de produção de que seres humanos são dotados.

O museu é uma pausa para a recuperação necessária da diversidade e inter-relações de materiais e circunstâncias, espaços e tempos. $\bigcirc$ próprio retorno é nova experiência. Há encontros e reencontros, choques e "viagens".

Nada do que é humano me é estranho e tudo pode ser apreendido e apreciado (uma pequena variação do clássico provérbio latinol. Museus são espaços singulares de conhecimento, emoções e prazer, e gostaria que assim continuassem a ser porque existem para os usuários comuns, "normais".

É claro que devem também ser atraentes, bem organizados internamente, bem sinalizados, dotados de adequado material informativo, com todos os atributos de museus bem administrados, conservados e socialmente inseridos. Acima de tudo, porém, devem ser experiências emocionantes de conhecimento, não apenas para os especialistas que organizam a estruturação física e espacial, a conservação, a preservação do acervo como um todo e da parcela exposta, mas especialmente para os visitantes, que mesmo sem dispor da erudição e das especializaçōes ali concentradas, são ou deveriam ser o alvo principal dos trabalhos.

O segundo aspecto sobre o qual teço algumas considerações tem a ver com a minha preocupação com questões epistemológicas, teóricas e metodológicas e experiência de historiadora, de professora de história, de 
formadora de historiadores, o que suponho venho sendo nos últimos anos.

Não conheço todos os tipos de museus nem as suas possibilidades de estruturação, mas acredito que em todos há o espaço necessário para um especialista entre tantos outros - o historiador - plenamente capacitado a inserir os objetos, quaisquer que sejam, em seu contexto social de produção e significação. Historiadores devem estar em todos os museus e não apenas nos históricos, pois todos, no fundo, são construções histórico-sócio-culturais, datadas e limitadas.

A complementaridade, a possibilidade de circulação e de colaboração de historiadores com essas instituições não deve ultrapassar certos limites, os quais não têm sido claramente colocados.

Há uma certa tradição ocidental de envolvimento entre História e campos correlatos, especialmente no período do Renascimento, com a valorização de objetos e textos antigos, na formação de coleções, nos procedimentos de taxionomia e critérios de relevância (Furet s.d.). Historiadores se envolveram não apenas como colaboradores e usuários, mas eventualmente como dirigentes e orientadores de trabalho de instituições tais como arquivos, bibliotecas e museus.

Essas relações nem sempre foram tranqüilas e de resultados satisfatórios. Na prática, a diferenciação de campos profissionais foi sendo concretizada, de modo a demarcar claramente as especificidades de cada campo de trabalho. Existem hoje como profissões definidas, as de arquivistas e museólogos, com formação apropriada para cada atividade.

Nos países em que a tradição de historiadores como dirigentes de instituições correlatas se manteve, ocorreu a criação de carreiras profissionais especializadas em cada tipo de instituição, o que levou à autonomia do trabalho especializado, libertando-o das eventuais injunçōes historiográficas.

De um lado, considero a idéia de definir um museu de história como laboratório de história, uma possível geradora de confusão e conflitos estéreis, pois ainda não está claro na comunidade acadêmica o que está sendo entendido como um laboratório de história.

Sinto-me responsável por isto, pois tenho proposto a formação de laboratórios de pesquisa em história desde alguns anos. Apesar das várias discussões e de alguns laboratórios estarem sendo implantados em algumas universidades, não há ainda suficiente clareza a respeito do que eles sejam, nem de seus limites e objetivos.

Pela proposta original, os laboratórios de história do Departamento de História-FFLCH/USP teriam como finalidade a articulação dos pesquisadores em áreas conexas de trabalho de pesquisa. Estas corresponderiam às especialidades com perfil melhor definido: História da Cultura, História Econômica, História dos Movimentos Sociais, etc., independentemente de teorias, métodos e técnicas de pesquisa. Disciplinas de graduação, experiências em iniciação científica, disciplinas de pós-graduação, pós-doutoramento e as pesquisas docentes convenientemente reunidas e inter-relacionadas visariam permitir já na graduação a especialização precoce - adiantando também o processo de formação de mestres e doutores através da seleção de disciplinas de uma mesma área, compondo a grade curricular com três ou quatro experiências em laboratórios diversos.

A própria complexidade da estrutura, juntando pesquisadores de tradição e trajetórias individuais em projetos que deveriam ser consensuais e 
articulados, dificultou sua implantação.

Em função dos problemas encontrados, o Departamento está atualmente montando laboratórios de grupos de pesquisa, isto é, equipando um espaço, alocado ao professor, com móveis, computador e impressora, ligação com a rede Internet, a partir de projetos definidos e financiados por agências, como $\mathrm{CNPq}$, CAPES, VITAE e FAPESP. Cabe ao docente ou aos docentes orientadores a estruturação do projeto de pesquisa, sua tramitação pelas agências financiadoras, a seleção de bolsistas, a orientação dos projetos, a articulação entre os diversos niveis de atividades, os relatórios de pesquisa, a seleção de material para publicação, etc.

O que são esses laboratórios de grupos de pesquisa? Até o presente momento, experiências iniciais com projetos de pesquisa orientada, tentativas de projetos coletivos, tentativas de ultrapassar a formação de pesquisadores isolados, propostas e apostas para o futuro. Todos submetidos ao controle externo, via agências financiadoras, com duração limitada e apresentação obrigatória de resultados periódicos.

Como funcionarão os laboratórios de grupos de pesquisa, a médio prazo? Quantos se transformarão em atividades integradas e quantos permanecerão individualizados? Quantos serão laboratórios de pesquisa coletiva? Quantos serão experiência formadora e integradora de pesquisadores em diversos niveis, da iniciação ao pós-doutoramento? Quantos sobreviverão e serão produtivos? Não podemos prever.

Vamos transferir a experiência em andamento para os museus históricos?

Considero que museus, como instituições de pesquisa, devem obrigatoriamente possuir projetos de pesquisa institucional explícita, também chamada de pesquisa pública (Rodrigues, 1952), realizada e orientada por seus quadros de pesquisadores, com objetivos claramente definidos, programas de pesquisa, tempo delimitado e apresentação pública dos resultados, quer através de publicações, quer através de exposições.

Não seria melhor institucionalizar a pesquisa pública nos museus inicialmente, antes de propor sua transformação em algo novo? Não seria melhor verificar os resultados iniciais dos laboratórios de pesquisa em História, antes de definir qual o tipo de laboratório desejável? Pela observação dessa fase preliminar, poderá haver diversos tipos de laboratório. Quais deles serão os mais adequados para os trabalhos a serem desenvolvidos nos museus, no espírito da pesquisa pública?

Por outro lado, chamo a atenção para as freqüentes propostas de historiadores de interferir em outras especialidades, abandonando as respectivas especificidades e trazendo-lhes problemas epistemológicos, teóricos e metodológicos da História.

lembro-me de propostas assemelhadas serem colocadas em relação aos arquivos, principalmente aos históricos.

Nos anos 70 e 80, alguns historiadores começaram a questionar o processo de organização dos arquivos históricos, principalmente na França. Propunham uma estruturação diferente da que existia, questionando a viabilidade de arquivos tradicionais (na organização, no conteúdo ou no suporte) darem conta das necessidades de pesquisa dos historiadores, naquele momento. Como 
se arquivos existissem apenas para pesquisadores em História ou como se historiadores não transformassem em objefo de estudo outras fontes e outros materiais documentais, que não os tradicionais, porventura guardados em arquivos?

Quase no mesmo momento em que historiadores da história econômico-social quantitativa propunham novos tipos de arquivos, que possibilitassem seus trabalhos com variáveis previamente escolhidas, outros historiadores estavam concretizando novas práticas historiográficas, com novas fontes, novos objetos, novas formas de análise, independentemente dos arquivos existentes. Reclamavam alguns dos arquivos que existiam e outros já estavam fazendo a "Nova História"!

A rápida mutação das características dos estudos históricos nos últimos cinqüenta anos deve remeter-nos sempre às cautelas necessárias no que diz respeito às propostas de interferência em outras áreas de atividades, que também sofrem transformações em decorrência de contexto social e tecnológico. As muitas formas de se fazer História e as chamadas Ciências Históricas devem ser levadas em consideração, bem como os postulados epistemológicos, teóricos, metodológicos e técnicos que direcionam os projetos, selecionam objetos, fontes e formas de interpretação (Bédarida, 1995).

Por outro lado, as experiências nacionais de historiadores organizarem arquivos históricos ou acervos documentais, sem a preocupação de conhecer e compreender os princípios que regem a organização de arquivos e acervos internacionalmente, deixou trágicos rastros de desarranjo e destruição de acervos documentais.

Claro que problemas de tal monta não ocorreriam sob a orientação segura de pesquisadores e orientadores experientes como o prof. Ulpiano. Mas o que poderia acontecer pelo país, como um efeito multiplicador, se cada historiador, na direção de um museu histórico definisse que o seu objeto de pesquisa pessoal seria o objeto do laboratório de história no museu?

Se historiadores profissionais, na grande maioria dos casos, dificilmente conseguem se comunicar com o público letrado de seu país, como pode ser observado pelas baixas tiragens das obras especializadas e também pela crescente separação entre o que é o conhecimento histórico especializado e o do cidadão (Russo 1995), como o fariam no caso da transformação dos museus históricos em laboratórios de pesquisa?

Quem cuidará do visitante comum, que procura apreender algo em sua caminhada pelo museu? Terão os museus históricos o mesmo destino de quase ininteligibilidade e desconhecimento que acompanha a História como processo de conhecimento?

E a quem caberia o controle externo e a verificação da apresentação de resultados? $\bigcirc$ que seria feito dos acervos museográficos toda vez que mudasse a direção da instituição? E como ficariam os projetos de pesquisa institucionais?

Como evitar que cada pesquisador transforme o seu projeto individual no projeto do museu histórico e não utilize o trabalho conjunto para seus projetos pessoais? Como evitar a manipulação ideológica?

Acredito que com a pequena tradição de pesquisa pública existente no país, a transformação de museus em laboratórios de história poderá vir a ser catastrófica, destruindo o pouco que existe no contexto museográfico e implantando projetos de pesquisa individuais como norma de trabalho. 